\title{
COVID-19: a cause of recurrent Graves' hyperthyroidism?
}

\author{
S. Jiménez-Blanco ${ }^{1} \cdot$ B. Pla-Peris ${ }^{2} \cdot$ M. Marazuela $^{1}$ (D)
}

Received: 4 August 2020 / Accepted: 28 September 2020 / Published online: 6 October 2020

(C) Italian Society of Endocrinology (SIE) 2020

To the Editor

Although recent evidence suggests that COVID-19 can affect practically all organs, data on the impact of SARS$\mathrm{CoV}-2$ on the thyroid gland are very scarce. Two patients with Graves' disease (GD) and COVID-19 have been recently published [1], and we would like to provide more evidence with two more cases.

Patient 1 was a 45-year-old woman with a 12-year medical history of GD. She had 2 previous episodes of hyperthyroidism that were treated with antithyroid drugs (ATD), first in 2008 after diagnosis (ATD for 22 months) and then at a relapse in 2015 (ATD for 25 months). She also had Graves' ophthalmopathy that was treated with corticosteroids for 3 months in 2018. At the beginning of March 2020, her thyroid function was normal, with free thyroxine levels (FT4) of $1.36 \mathrm{ng} / \mathrm{dL}$ (normal range, $0.93-1.7 \mathrm{ng} / \mathrm{dL}$ ) and serum thyroid-stimulating hormone levels (TSH) of $0.75 \mu \mathrm{IU} /$ $\mathrm{mL}$ (normal range, $0.27-4.2 \mu \mathrm{IU} / \mathrm{mL}$ ), although anti-TSH receptor antibodies (anti-TSHR-Ab) were slightly elevated $(1.9 \mathrm{mIU} / \mathrm{mL}$; normal range $<1.5 \mathrm{mIU} / \mathrm{mL})$. In May 2020, she developed bilateral pneumonia and was diagnosed with SARS-CoV-2 infection. This patient also presented palpitations and nervousness. Her blood test results showed a TSH of $<0.005 \mu \mathrm{IU} / \mathrm{mL}$, a FT4 of $>7.7 \mathrm{ng} / \mathrm{dL}$ and an anti-TSHR$\mathrm{Ab}$ of $28.7 \mathrm{mIU} / \mathrm{mL}$. Thyroid ultrasound showed hypervascularization. She started methimazole (MMI) at a daily dose of $40 \mathrm{mg}$, which resulted in a rapid normalization of her thyroid function. No deterioration of her ophthalmopathy was observed. The MMI dosage of $40 \mathrm{mg} /$ day was reduced to $5 \mathrm{mg}$ /day during follow-up and she shows improvement in her condition after 3 months of treatment.

M. Marazuela

monica.marazuela@salud.madrid.org

1 Department of Endocrinology and Nutrition, University Hospital of La Princesa, Madrid, Spain

2 Department of Endocrinology and Nutrition, Hospital Arnau de Vilanova, Valencia, Spain
Patient 2 was a 61-year-old woman with a history of atrial fibrillation and GD (diagnosed in 2004) with one GD relapse in 2014. Both episodes were treated with ATD. She had had normal thyroid function since 2016. One month after her diagnosis of COVID-19 in March 2020, she was hospitalized in the Coronary Care Unit. Physicians suspected between an infarction with non-obstructive coronary arteries or myocarditis. During hospitalization, the patient had palpitations. Thyroid function tests showed TSH at $<0.001$ $\mu \mathrm{IU} / \mathrm{mL}$ (normal range, $0.27-4.2 \mu \mathrm{IU} / \mathrm{mL}$ ), FT4 at $2.66 \mathrm{ng} /$ $\mathrm{dL}$ (normal range, 0.93-1.7 ng/dL) and anti-TSHR-Ab at $1.31 \mathrm{IU} / \mathrm{L}$ (normal range $<0.5 \mathrm{IU} / \mathrm{L}$ ). Radionuclide thyroid scanning showed increased uniform tracer uptake and thyroid ultrasound showed hypervascularization. She started treatment with $10 \mathrm{mg}$ of MMI with clinical and biochemical improvement. Three months later, the patient has reached euthyroidism. She continues with a daily dose of $5 \mathrm{mg}$ of MMI.

In conclusion, we describe two documented cases of concurrent presentation of SARS-CoV-2 infection and GD. Regarding thyroid function, both patients had previous history of GD but they were in remission and had maintained a normal thyroid function prior to contracting SARS-CoV-2 infection. The temporal sequence suggests that GD could have been triggered by SARS-CoV-2 infection. Viral infections are frequently cited as a major environmental factor involved in the pathogenesis of autoimmune thyroid diseases [2]. In addition, the hyper-inflammatory disease associated with severe SARS-CoV-2 infection could have triggered an immunological cascade with reactivation of GD, as has been described in other autoimmune disorders. It is of interest that whereas the inflammatory phenomenon induced by SARS$\mathrm{CoV}-2$ seems to be mainly mediated by Th1 cytokines as well as IL-6, the pathogenesis of GD is apparently mediated by a Th2 autoimmune response. However, different studies have reported increased levels of IL-6 in patients with GD [3]. In addition, it is worth remembering that this cytokine may exert many different and complex effects through their two mechanisms of interaction with its cellular receptor. Finally, different and interesting recent data on the role of 
novel Th lymphocyte subsets (e.g., Th17, Th22) and their cytokines on the pathogenesis of Autoimmune Thyroid Disease (AITD), indicate that the Th1-Th2 paradigm regarding the pathogenesis of Hashimoto thyroiditis and GD requires to be revisited [4]. Other potential mechanisms, such as stress, could have also had a role in the Graves' relapse [5]. Attentive monitoring of thyroid function is recommended, especially in patients with previous autoimmune thyroid disorders, to avoid overlooking the diagnosis and treatment delays.

Acknowledgements To Carolina Knott for kindly reviewing the manuscript.

Funding The authors received no specific funding for this work.

\section{Compliance with ethical standards}

Conflict of interest There are no conflict of interest.

Ethics approval All procedures performed were in accordance with the ethical standards and with the 1964 Helsinki Declaration and its later amendments.

Research involving human participants and/or animals All procedures performed during this retrospective study were in accordance with the ethical standards of the institutional and/or national research committee and with the 1964 Helsinki declaration and its later amendments or comparable ethical standards. The ethical committee approval is not required for case reports.
Consent to participate Not applicable.

Informed consent Informed consent was obtained from both patients. Data were anonymized.

\section{References}

1. Mateu-Salat M, Urgell E, Chico A (2020) SARS-COV-2 as a trigger for autoimmune disease: report of two cases of Graves' disease after COVID-19. J Endocrinol Investig [Internet]. 0123456789:23. https://doi.org/10.1007/s40618-020-01366-7

2. Prummel MF, Strieder T, Wiersinga WM (2004) The environment and autoimmune thyroid diseases. Eur J Endocrinol 150(5):605-618

3. Salvi M, Girasole G, Pedrazzoni M, Passeri M, Giuliani N, Minelli $R$ et al (1996) Increased serum concentrations of interleukin-6 (IL-6) and soluble IL-6 receptor in patients with Graves' disease. J Clin Endocrinol Metab 81(8):2976-2979

4. Li Q, Wang B, Mu K, Zhang JA (2019) The pathogenesis of thyroid autoimmune diseases: new $\mathrm{T}$ lymphocytes-cytokines circuits beyond the Th1-Th2 paradigm. J Cell Physiol 234(3):2204-2216

5. Vita R, Lapa D, Trimarchi F, Benvenga S (2014) Stress triggers the onset and the recurrences of hyperthyroidism in patients with Graves' disease. Endocrine 48(1):254-263

Publisher's Note Springer Nature remains neutral with regard to jurisdictional claims in published maps and institutional affiliations. 